\title{
Should we routinely place an indwelling ureteral stent post-ureteroscopy?
}

\author{
Sero Andonian, MD, MSc, FRCSC, FACS
}

Department of Urology, McGill University, Montreal, QC, Canada

Cite as: Can Urol Assoc J 2020;14(2):69. http://dx.doi.org/10.5489/cuaj.6421

See related article on page 61

$\mathrm{O}$ rdonez et al have recently performed a Cochrane review of published randomized clinical trials examining the role of routine placement of an indwelling ureteral stent post-uncomplicated ureteroscopy. ${ }^{1}$ They included 23 studies with 2656 randomized patients. ${ }^{1}$ They found that stenting did not increase pain from postoperative days $0-3$. However, stented patients experienced more discomfort from postoperative days 4-30. Stenting did not increase the need for secondary interventions. In seven studies, stent placement reduced the need for narcotics. There was no difference in the development of postoperative urinary tract infection. Based on 14 studies, stenting was associated with a slightly reduced rate of ureteral stricture up to three months. Placing a ureteral stent increased operative time by an average of 3.72 minutes and reduced quality of life assessed in one study. Finally, stenting was associated with significantly lower rates of hospital re-admissions (risk ratio [RR] 0.70; 95\% confidence interval [CI] 0.32-1.55; low certainty of evidence). ${ }^{1}$

The strength of this latest Cochrane systematic review includes the inclusion of only randomized clinical trials examining stenting post-uncomplicated ureteroscopy. However, it suffers from several limitations. Despite including the highest level of available evidence, the certainty of evidence for most outcomes was rated either low or very low due to methodological deficiencies. Therefore, we cannot draw strong conclusions from this study for recommendations of routine stenting post-uncomplicated ureteroscopy. The second limitation is that it excluded studies that recruited children and pregnant women, patients with systemic signs of infection, anatomical abnormalities (including solitary kidneys and transplanted kidneys), and patients undergoing bilateral procedures. Complicated ureteroscopies, such as ureteral perforation and gross hematuria, were also excluded. The third limitation is that it did not examine the rates of postoperative dysuria, frequency, urgency, and hematuria. These are bothersome lower urinary tract symptoms that patients complain about most when they have indwelling

ureteral stents. The rationale to avoid routine placement of stents post-uncomplicated ureteroscopy would be to avoid these symptoms. The fourth limitation of the study is that it did not account for whether patients were admitted postureteroscopy. Except for two studies performed in North America, the rest of the 23 studies were performed elsewhere in the world, where patients are routinely admitted postureteroscopy and, therefore, easier to monitor. However, in Canada, ureteroscopy is performed as an outpatient procedure; as such, results of this Cochrane review may not be as applicable.

Based on this latest Cochrane review, there is no harm in placing a stent post-routine ureteroscopy. It may significantly reduce hospital re-admissions. According to the latest Canadian Urological Association guidelines, it is optional to place an indwelling ureteral stent post-uncomplicated ureteroscopy. ${ }^{2}$ Personally, I find routine placement of an indwelling ureteral stent post-uncomplicated ureteroscopy provides me with the security that the renal unit is adequately drained. If the patient returns to the emergency department with renal colic, I will not need to struggle to find the ureteral orifice due to trigonal inflammation and edema - a problem we have all been faced with. Therefore, it is not surprising that most (>90\%) patients who undergo ureteroscopy in Canada have an indwelling ureteral stent placement. ${ }^{3}$

Competing interests: The author reports no competing personal or financial interests related to this work.

\section{References}

1. Ordonez $M$, Hwang $E C$, Borofsky $M$, et al. Ureteral stent versus no ureteral stent for ureteroscopy in the management of renal and ureteral calculi: A Cochrane review. Can Urol Assoc J 2019 July 23; Epub ahead of print. http://dx.doi.org/10.5489/cuai.5957

2. Ordon M, Andonian S, Blew B, et al. CUA guideline: Management of ureteral calculi. Can Urol Assoc J 2015;9:E837-51. https://doi.org/10.5489/cuai.3483

3. Muslumanoglu AY, Fuglsig S, Frattini A, et al. Risks and benefits of postoperative double-J stent placement after ureteroscopy: Results from the clinical research office of Endourological Society Ureteroscopy Global Study. J Endourol 2017;31:446-51. https://doi.org/10.1089/end.2016.0827

Correspondence: Dr. Sero Andonian, Department of Urology, McGill University, Montreal, QC, Canada; Sero.andonian@muhc.mcgill.ca 